\title{
Daniel Link y la televisión:ensayos entre la clase y la cualificación
}

\section{Catalin, Mariana}

Resumen:

El presente artículo busca analizar el lugar que ocupa la televisión en relación con el arte y la literatura en la producción ensayística de Daniel Link. Para esto, en una primera instancia, se realiza un recorrido desde la postulación, en relación con la televisión, de la necesidad de un "punto de vista móvil" que se realiza en los ensayos de La chancha con cadenas hasta la forma en que el mismo se efectúa en Clases. Este recorrido pone en el centro los modos de relación del ensayista con lo que va definiendo como géneros y clases.

En una segunda parte, se abordan los textos que toman específicamente a la serie televisiva como objeto. Se

Cuadernos del Centro de Estudios de Diseño y Comunicación № 61

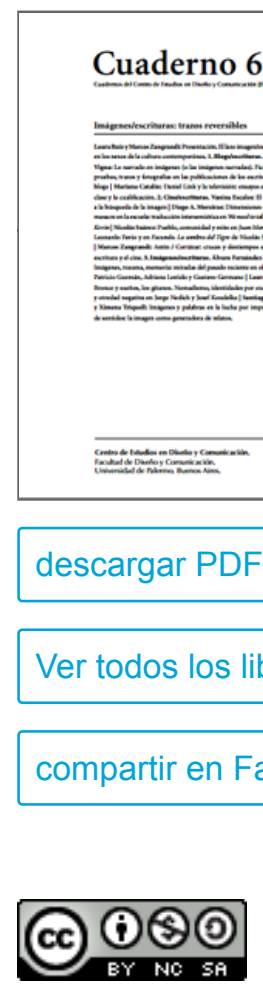

Esta obra está bajo una Licencia Creative Commons Atribución-NoComercialCompartirlgual 4.0 Internacional analizan aquí la necesidad del ensayista de armar escalas de valor, los modos en que las mismas se constituyen y la singularidad que, en este contexto, presenta el tratamiento de la serie Lost.

Palabras clave: televisión - arte - cultura - valor artístico - ensayo - Daniel Link.

(*) Doctora en Humanidades y Artes mención Literatura por la Universidad Nacional de Rosario. Ha sido aceptada para el ingreso a la carrera de Investigador del CONICET en categoría Asistente. Es, además, Jefe de Trabajos Prácticos en la asignatura Literatura Argentina I en la Facultad de Humanidades y Artes (UNR) y parte del equipo de dirección de la plataforma web Fiesta E-diciones.

En La chancha con cadenas (1994), su primer libro, Daniel Link sostenía, a propósito de la forma en que los narradores de la década de 1960 daban lugar a una "nueva literatura", lo siguiente: Las modificaciones en el aparato perceptivo (de orden histórico) aparecen atadas a la irrupción de nuevas tecnologías: ayer el cine, hoy las realidades virtuales. Es a partir de allí que las "nuevas percepciones" se construyen y sólo a partir de lo cual ciertos campos de representación se definen. (1994, p. 51) Sin duda, persiste en este enfoque cierta linealidad, 
que la reflexión posterior del autor sobre los imaginarios complejizará pero, al mismo tiempo, puede observarse ya el interés por los modos en que, tal como lo señala Jaques Rancière (2010), el arte en la era estética ha jugado y aún juega en torno a los medios que las nuevas técnicas y soportes pueden vehiculizar para despertar posibilidades sensibles agotadas.

Ahora bien, en el comienzo de Clases (2005), al mismo tiempo en que se insiste en reconocer las continuidades del juego, la aparición de nuevas tecnologías de la información y de la comunicación se liga a un salto sin precedentes: No soy (no seremos) tan optimistas como Baumann y otros teóricos igualmente milenaristas, pero lo cierto es que nos movemos en un tiempo (¿habría tiempo si no hubiese movimiento?) dominado por un salto tecnológico sin precedentes que las mentes más lúcidas del siglo pasado (Valery, Benjamin, Borges) habían a medias preanunciado: una utopía anárquica que entonces tenía la forma de la enciclopedia o el libro de los pasajes y que hacía de la mera actividad (y no del producto que de ella se deduce) la fuente de todos los goces estéticos y culturales. Y ese salto tecnológico es lo que nos obliga a pensar todo de nuevo (sobre todo el sentido y el lugar de la resistencia y la disidencia en el arte o, lo que es lo mismo, en el pensamiento). (2005, p. 16) En un final que, sin embargo, busca diferenciarse de los finales ya formulados (los milenarismos), el ensayista intenta pensar no sólo las nuevas formas que ese salto tecnológico habilita sino algo mucho más medular como "el lugar de la resistencia y la disidencia" en el arte.

En este contexto, el contacto, entendido en términos de Jean-Luc Nancy (1993, 2003, 2007), con las manifestaciones y productos de ese salto tecnológico, marca diferentes sectores de la producción de Link y supone la apelación a medios diversos. Sin duda, lo que ha llamado más la atención de ciertos sectores de la crítica y el periodismo cultural es el contacto con los formatos que surgen en relación con Internet: el chat como recurso en La ansiedad (2004) o los modos de la puesta en circulación de Monserrat (2006) en el blog del autor. Podría sumarse aquí la manera en que, desde el blog y a propósito del mismo, se formula una metodología que parece querer volverse un imperativo para la propia práctica (y que presenta como uno de sus rasgos principales el borrar los límites entre las diferentes formas en que ésta se pone de manifiesto)1.

Me interesa, sin embargo, en función de generar un punto de vista alternativo, centrarme en un medio marginal en ese salto que plantea Daniel Link: la televisión. Marginal porque, como tecnología, la televisión ocupa un lugar ambiguo. Si, según lo plantea Lev Manovich (2009), las cinco características que determinan la lógica de los nuevos medios productores de la transformación de la cultura en cultura electrónica son la representación numérica, la modularidad, la automatización, la variabilidad y la transcodificación, es evidente que la televisión no es la tecnología que define el presente. Antes bien, se presenta como deudora de los medios técnicos centrales de la modernidad en la medida en que muestra una sucesión de imágenes con las que el espectador no puede interactuar, es decir, no posee la lógica de la interfaz. Sin embargo, tampoco pertenece enteramente al pasado: habiendo sido el primer medio electrónico en difundir ampliamente una "pantalla en tiempo real", central en la temporalidad actual, adelanta, vehiculiza y expande ciertos aspectos de la lógica que, según Manovich, está redefiniendo la cultura visual existente2.

En la ensayística de Link, la televisión y sus productos ocupan también un lugar singular: no son parte central del "salto tecnológico sin precedentes" que está teniendo lugar (lo audiovisual es el pasado: "nuestra infancia sostiene Link en “Absurdo"- fue antes que nada audiovisual (iéramos tan jóvenes!)” [2005, p. 96]) pero, sin embargo, captan la atención del escritor tanto como para generar una etiqueta dentro del propio blog que habilita una fuerte intervención sobre los modos de plantear ciertos aspectos que definen el presente, algo que la radio o 
el cine ya no logran. Entre la plena luz de lo actual y el desfasaje que supone esa no pertenencia, cuando la televisión aparece en ciertos ensayos sobre literatura y cuando el ensayista se ocupa específicamente de algunos productos televisivos, se visualiza y, a la vez, se genera una serie de movimientos singulares en torno a una dinámica central en la producción ensayística del autor: la que se entabla entre el rechazo a la clasificación y la simultánea necesidad de cualificación en el arte, dos conceptos que terminan de volverse centrales en Fantasmas. Imaginación y sociedad (2009), pero que marcan toda su ensayística anterior. En este contexto, su abordaje permite reflexionar sobre la tensión que parece recorrer la escritura de Link entre el "gusto por los géneros" y la necesidad de sostener una diferencia entre la cultura y los modos de efectuación del arte -doble interés que, a pesar de estar supuesto en su sistema valorativo y constituirse como un elemento central en la construcción de su genealogía de escritor, vuelve en ciertas ocasiones de manera verdaderamente incómoda-3.

Literatura y televisión: inicios y genealogías

En el marco, entonces, de la importancia que se le otorga a las formas en que las nuevas tecnologías modifican las percepciones, en la Introducción a La chancha con cadenas la televisión es utilizada para definir una pertenencia generacional. Y en esa definición se juega ya la relación entre literatura y cultura: Las hipótesis que aquí se manejan en relación con la literatura argentina son hipótesis que afectan al conjunto de la cultura argentina. La literatura, simplemente, muestra mejor las direcciones y las tensiones culturales. Esas hipótesis son generacionales: nací en una generación que todavía lee (o leía) pero que también mira (o miraba) televisión. Las primeras discusiones estéticas o metafísicas que seguramente hemos sostenidos tenían que ver antes con algún aspecto de Astroboy o una trama particularmente oscura de Startrek. Es por eso por lo que leemos con un "punto de vista móvil", que a veces coincide con el de la cultura "alta" y a veces con el de la cultura de masas. Y es por eso, también, por lo que nos importa particularmente la articulación entre los diferentes lenguajes de la literatura y de los medios masivos, entre la lengua universal a la que la literatura aspira, la lengua general que ilusoriamente pretenden imponer los medios y los lenguajes particulares que circulan socialmente. En estos juegos de lenguaje se encuentran (a veces encerrados) los debates culturales del siglo XX. (1994, p. 9) La literatura, en su relación con la cultura es, en el comienzo de esta explicitación, "simplemente" un lugar desde donde mirar mejor ciertas cosas. Pero, como no solo se ha leído sino que también se ha visto televisión, lo que le interesa al ensayista, en última instancia, son las articulaciones: poder moverse entre los dominios que, si bien en el comienzo de la cita son inclusivos, luego parecen ponerse en paralelo. A lo largo del libro, el pretendido punto de vista móvil se concreta antes que nada en el armado de conexiones: es lo que habilita la composición de ciertas genealogías que en el momento de la compilación de La chancha con cadenas podían ser provocadoras. En el ejemplo inmediatamente posterior a la cita que introduje, Aira es puesto en contacto con Borges, Cortazar y Puig mediante la apelación a ciertos juegos de lenguaje que requieren tener en cuenta el "horizonte de la cultura popular" -horizonte que, sabemos, no es equivalente a lo masivo pero que en la articulación del ejemplo busca serlo-. Lo mismo ocurre cuando se conecta a Borges con Puig, Masotta y Warhol a partir de la atribución al primero de la edificación de "un monumento a la cultura de masas" (1994, p. 29); o, cuando en una argumentación que desencadena mediante la apelación a los mass media, Viñas queda ligado al boom pero también a Puig y a Cortazar4.

Ahora bien, este punto de vista móvil, incluso con estas limitaciones, parece volverse un imperativo ajeno al objeto cuando se aborda la figura de Rodolfo Walsh. El primer apartado de "Los setenta, Walsh, y la novela en crisis" se titula "Literatura y tecnologías": en él se intenta armar un contexto para la lectura de dicho autor a partir de los ejes que se han tratado en los desarrollos anteriores. Pero para eso la promesa del título se defrauda: si 
bien se ponen en escena las figuras de los ensayos precedentes el término tecnología queda reducido a "tecnologías narrativas" y la relación con la industria cultural no parece armar una verdadera serie entre los textos que se quieren presentar. Si para el ensayista la frivolidad supone el "estar preso de un sistema de convenciones de los otros, de un sistema de reglas de cortesía de los otros (que algunos llaman lengua, otros cultura, otros neurosis)" (1994, p. 92), hay algo de frívolo en esa explicitación del comienzo que parece obedecer a las exigencias de la compilación como género al imponer un imperativo al que el objeto no responde. Incluso, si observamos detenidamente el resto de las conexiones armadas en los ensayos, eso que se elegía poner en el origen como elemento detonante del punto de vista se ha perdido: si lo masivo surgía en el prólogo motivado por la reflexión sobre ejemplos concretos de la televisión, en los ensayos "las masividades" que va construyendo el autor o bien son abstraídas (apelan a la serialización y al trabajo antiartesanal, adelantando el futuro interés por el pop, o a la tecnificación y el montaje), o bien suponen otros medios con características diferentes (fundamentalmente el cine). Y, sin embargo, al borde de la frivolidad, las series se generan. Hay tal vez ya aquí el señalamiento de un modo que se observa justamente a partir del lugar que se le quiere dar a la televisión y, a través de ella, a la cultura de masas: entre la necesidad de (y el gusto por) la explicitación de imperativos (preceptos) críticos y el saber que le dice que hay que resistirse (que se observa, claramente, en este caso en la manera en que se define lo frívolo), entre los modos de esas resistencias y las insistencias del interés se juega parte de la singularidad y del poder de la escritura ensayística de Daniel Link.

En Cómo se lee y otras intervenciones críticas (2003) el imperativo del punto de vista móvil se reformula, también en el prólogo, en el interés por los "límites de la literatura", por los bordes "en los cuales lo literario se confunde con otra cosa (o sencillamente desaparece)" (2003, p. 11). Pero la tecnología de la información y la comunicación que ocupa el centro aquí es ya explícitamente Internet: la reproducción digital y las preguntas que ésta habilita sobre la posición del intelectual, sobre la redefinición de los límites del campo y sobre las formas de democracia en general. En paralelo, la relación entre cultura y arte se complejiza.

Esto se observa claramente en la reflexión de Link sobre los géneros discursivos.

En "Género y cultura", que funciona como introducción al apartado que se les dedica, el interés por los géneros se justifica por su importancia en relación con la "producción cultural", con "la manera natural con que la gente se acostumbra a manejar categorías nada naturales" (2003, p. 93), por lo que la lógica genérica queda ligada desde el comienzo a la "clase". A propósito del policial y al hablar nuevamente del caso Walsh, los mismos son definidos, siguiendo a Benedetto Croce, como "falsos universales y sistemas de constricción ajenos al arte" (2003, p. 110): "Es que hay algo de la literatura que escapa a las poéticas de los géneros y, en el siglo XX, ese algo es sencillamente lo que se reconoce como literatura" (2003, p. 110). Sin embargo, por una parte, se pone de manifiesto en la argumentación del autor, que es la relación incómoda y no simplemente el escapar de esas matrices lo que puede dar lugar a la experiencia literaria. Por otra parte, emerge en los modos de la argumentación algo tal vez menos evidente y que podría volver incómodas esas mismas definiciones que se han formulado en el íncipit como imperativos (sin las cuales, sin embargo, el movimiento del ensayo no habría tenido lugar): la erudición que se despliega en torno a esos sistemas de constricción da cuenta de la potencia de un interés que no parece agotarse en la obligación de impugnar la naturalización de ciertas formas de dominación ni en la necesidad de acercarse al acontecimiento artístico.

Es en este contexto, al hablar específicamente del melodrama, donde aparece la única mención extensa del libro a un producto televisivo: Seinfeld. Sin embargo, la misma consta de apenas cinco párrafos y se presenta 
como un agregado introductorio en función de un objetivo previo: recuperar un texto y generar una presentación más atractiva mediante la mención de la sitcom, género que hace "las delicias de la programación por cable". Ahora bien, si en vez de rastrear la mención explícita, se buscan las formas de insistencia del interés (Deleuze, 2002), es justamente en función de la reflexión sobre la ciencia ficción como producto de la cultura industrial y su relación con la literatura, en donde se explicitan algunas de las preguntas que movilizarán la mirada cuando la televisión sea objeto. Interés que se debatirá, al intentar valorar la trilogía sobre Marte de Kim Stanley Robinson, también entre el arte como efectuación y la norma institucional de la cultura5: La terraformación, hay que admitirlo, es bastante verosímil. Tediosa, pero verosímil. Los momentos descriptivos que la novela consagra a Marte (y son muchos) están bien logrados y suscitan la atención casi siempre. Pero no es por esto que conviene leer esta trilogía abrumadora. Es porque allí están representados los terrores de hoy: la explosión demográfica, las políticas migratorias y la vejez, todo aquello que puede acabar con "la humanidad": un manual de biopolítica actual.

¿No son esos los problemas (agotamiento de recursos naturales, vejez, políticas migratorias) los que hoy (al comienzo de un milenio azotado por guerras de imprevisibles resultados) ponen en crisis las nociones de humanidad y exigen, ya, respuestas ontológicas y políticas? (Link, 2003, p. 137) Ahora bien, será recién en Clases donde la mención de Seinfeld pase a ser un factor central en la argumentación y recupere el punto de vista móvil en función de ese elemento primigenio que se elegía para figurar el propio origen. Si en el Prólogo de Cómo se lee se mencionaban ya ciertos retiros (de la civilización y de la cultura), Clases se torna más radical y crea como contexto para la propia escritura, tal como lo planteé en la introducción, "un salto tecnológico sin precedentes", que reconoce, sin embargo y sin por eso anular la radicalidad, finales preexistentes. $Y$ en este "Umbral", para definir lo que se quiere hacer, se vuelve fundamental ese elemento que ya habíamos puesto en discusión en torno a la relación arte-cultura-género: las clases. Estas se presentan, en primer lugar, a través de la mención de los hackers y, luego, en relación con la propia actividad (ser profesor) y se las define como "dispositivos de captura y disciplinamiento", "ficciones normalizadoras", "dispositivos de exterminio". En este contexto, lo que se busca leer es lo que "hay de resistencia a la captura, al disciplinamiento, a la normalización y al exterminio" (2005, p. 19) en ciertos textos literarios emblemáticos, a pesar de que, previamente, en una nota al pie, se haya sostenido que se apela a ejemplos no literarios como Internet justamente para que "nadie piense que sostenemos una hipótesis autonomizante sobre la literatura" (2005, p. 17$) 6$.

El caso Seinfeld se introduce específicamente en "Absurdo" en función de la reflexión sobre la relación entre arte y política en torno al teatro del siglo XX, cuyo abordaje se justifica desde el comienzo por ser el antecedente directo de la cultura industrial (término que se vuelve caro a Link en este libro). En la medida en que la comedia de situación ha reemplazado, sostiene el ensayista, a la comedia en tanto modelo de interpretación y formalización de los comportamientos, los productos televisivos que se encuadran bajo su égida (la sitcom como género y el reality show, géneros altamente serializados que "la cultura actual explota hasta el cansancio" [2005, p. 101]) se constituyen en sitios privilegiados de observación del debate en torno a los derechos y a las formas de la biopolítica. Coherentemente con este postulado, Seinfeld es en una primera instancia utilizada como documento: "Ese emblema de nuestra cultura finisecular" permite observar "más claramente" "que además de todos los finales (de un siglo, de un milenio, de una comedia de situación), lo que se termina también es esta idea de cultura sobre nada" (2005, p. 102). Ahora bien, es justamente esto que no necesariamente la convierte en arte (de hecho la afirmación surge de pensar cómo se debaten derechos en la televisión no de cómo se impugna la cultura o se desdeña en bloque el sistema de clasificación, que era lo que en el comienzo del ensayo 
definía al arte, antes que a su adjetivación como político), lo que habilita que sea igualada a Pinter y a Beckett en tanto lugar para "verificar" que "el arte nada dice o traza salvo el umbral de una mutación antropológica" (2005, p. 110). Así, paradójicamente, cuando se convierte en "emblema" puede salirse de la clase (de su clase). Pero fuga la clase no sólo por esa relación, que en última instancia busca "verificar", sino porque cuando se la utiliza de ese modo y, a pesar incluso de esa articulación, Seinfeld permite esbozar formas singulares de valoración que enrarecen la definición del comienzo de "arte político". Esto se observa en el modo en que el ensayista analiza su final. Link acuerda con la opinión de los fanáticos de que el final de la tira ha sido malo por moralista y aburrido, planteando la posibilidad de que esa lógica podría haber producido otro tipo de desenlace sí valorable: que no fuera moralista (que no capturara y disciplinara) y que no fuera aburrido (es decir que obedeciera a los requerimientos de la clase a la que el producto pertenece). Seinfeld, la televisión, en su relación extañada con Pinter y Beckett, obliga así a Link a enfrentarse con modos de valoración que antes que resistir a la sensibilidad milenarista (imperativo que se plantea en el mismo ensayo) surgen en relación con ella, generando así una verdadera movilidad de la mirada: al final del ensayo no se puede más que sostener, sin la protección de la simulación que se proponía en "Pop", que si el cóndor antes pasaba, "hoy está prácticamente extinto".

La televisión como objeto: "Diario de un televidente"

Ahora bien, hay un lugar en que la televisión no es igualada a aquello que se considera arte (lo que hacía emerger una relación incómoda con la clase pero, al mismo tiempo, justificaba en última instancia la apelación de ese ensayista que se figuraba "mirando al cielo" del "arte experimental" en función del ejemplo) sino que se convierte en objeto específico de la escritura y en medio para la intervención. Ese lugar es la etiqueta "Diario de un televidente".

La misma ha servido para reunir, a partir de enero de 2007 y en el marco del blog, una serie de textos sobre objetos disímiles relacionados con ese medio, alguno de los cuales han sido posteriormente incluidos en Textos de ocasión, en un apartado que respeta la denominación de la etiqueta. En el orden que impone la compilación, el surgimiento específico del interés por lo que se produce en ese medio se relaciona con la posibilidad de un nuevo modo de ver televisión que se consolida durante 2007 (y que no casualmente arma una "red" de tecnologías).

Algo a lo que el ensayista otorga el carácter de "revolucionario": el acceso, gracias a internet, "al alcance de cualquiera, de los programas que uno quiere ver, para verlos cuando quiera y como quiera" (2012, p. 237). En este sentido, si bien los textos que se reúnen en esta etiqueta se ocupan tanto de la transmisión de los juegos olímpicos como de las diferencias y similitudes entre Mirtha Legrand y Susana Giménez, en función de ese "modo de ver" hay un género que capta centralmente la atención del ensayista: la serie televisiva7.

En los textos en que Link se aboca al análisis de las series televisivas, a diferencia de lo que ocurre cuando se ocupa de otros avatares ligados a la televisión, las mismas son presentadas antes que nada como objetos a ser valorados. En el texto que se elige poner en primer lugar en el apartado, el ensayista sostiene: Miro televisión, leo libros, asisto a representaciones teatrales, lo que sea, por placer (...) Pero ese placer, como es un placer intelectual, no es nunca ajeno a la calidad de la construcción a la que me someto: imagino, formulo hipótesis, calculo como ha sido hecho eso que me arrastra. (2012, p. 237) El placer (no el goce) es lo que iguala la relación del ensayista con los productos de diferente índole que elige presentar8. Pero si en Clases, Seinfeld 
podía funcionar como emblema sin necesidad de introducir explícitamente el problema de la calidad, aquí se coloca la aclaración en el comienzo, casi como una prevención: el ensayista, en tanto intelectual, nunca puede (debe) ser ajeno a la calidad de la construcción. Sin embargo, el ímpetu clasificatorio puede obedecer también a una lógica que impone la serie televisiva: el gusto por la recomendación ("Mi amiga nunca vio Lost y yo repliqué a sus ataques maníacos con los míos: tenía que verla, iba a encantarle" [2012, p. 248]). El ensayista se ve obligado, compelido, tanto por un posible imperativo intelectual, que queda en el borde de ser moral, como por la lógica de lo que se elige mirar (a la que no puede más, entonces, que reproducir), a armar escalas de valor.

Ahora bien, si en esta autofiguración inicial se apela a la igualación de dominios, en los textos reunidos en el apartado del libro, la literatura (el arte) casi no se menciona y la comparación no funciona como mecanismo para generar valor. No se aborda, tampoco, solo lo bueno: obedeciendo a la metodología que impone el modo de ver, el ensayista da cuenta también de lo "malo" (al descargar las series de Internet el espectador, a pesar de la investigación previa, se arriesga a un error prolongado, en la medida en que la descarga en la lógica de Link parece inhabilitar el zapping y obliga a terminar de ver, al menos, una temporada; casi una moral del espectador: "Siete veces me dormí en la mitad de un episodio u otro (...) Pero persistí, con la disciplina que me caracteriza, para que no me digan que prejuzgo" [2012, p. 261]). Cuando se deja una serie en la columna negativa de la lista, en primer lugar, es porque aburre: "Aburridísima al principio, la serie [Héroes] mejora a partir del capítulo 4 y después vuelve a caer en pozos de tedio" (2012, p. 238), "Dresden Files, una porquería soporífera", "la soporífera Mad Men", etcétera. Luego se desarrollan las causas: "unos personajes horribles, una producción tan berreta que asusta y unos guiones tediosos" (2012, p. 239) pero también la previsibilidad, la trivialidad, la pérdida total de la verosimilitud histórica, el reinado epidémico de la psicología, la reduplicación de los mecanismos de captura a través de la estatización de lo monstruoso, la burocracia narrativa, la obediencia a un capricho subrayativo o demostrativo, la tendencia hacia las tercas moralidades.

El aburrimiento se presenta así como una manera de ligar los criterios poniendo en primer lugar la lógica que predomina en aquello que se aborda; lógica que puede luego ser desarmada en función de criterios tal vez más propios de otros campos de interés.

Pero, al mismo tiempo, el aburrimiento es algo que el yo padece, que lo afecta, por lo que lo aburrido no sólo da lugar a la invectiva que muchas veces clausura las posibilidades de continuar la escritura, sino también a la narración de la anécdota personal, que se extiende ya sea sobre los modos en que se llegó al sueño o sobre los enfrentamientos con aquellos que defienden lo que Link no quiere ver9.

En la determinación de lo que sí hay que ver (o de lo que, en última instancia, se puede ver "sino con alegría al menos sin desagrado" (2012, p. 261) ya que entre lo que no aburre hay gradaciones) es fundamental sin duda el "de qué hablan" las series: hay, en el abordaje, un constante intento por determinar el tema que supera la necesaria descripción argumental (“¿De qué habla Dr. Who, con una inteligencia incomparable?”). Aquí se repite el interés biopolítico que generaba Seinfeld y las preguntas e intereses que marcaban el abordaje de los géneros literarios, las obsesiones del ensayista: el interrogante por cómo vivir juntos; la reflexión sobre los mundos posibles y la multiplicidad de lo viviente (y los conflictos en torno a su destrucción); la presentación de estirpes monstruosas que "están fuera de la clase (social, naturalmente) al mismo tiempo que fuera del género y la genealogía" (2012, p. 255). Y es que, a pesar de que se valora cuando se escapa de ellos, los géneros se vuelven fundamentales, pero no por su posible carácter literario sino paradójicamente como matrices que determinan un gusto previo, en función del cual, muchas veces, se decide qué descargar: el realismo queda 
totalmente descartado ("el vómito de los estereotipos"); el melodrama y el policial pueden ser atractivos siempre y cuando el segundo responda coherentemente a la pregunta de por qué se mata o se ocupe de asesinos seriales; y la ciencia ficción, que podría agrupar a Doctor Who, Lost y Fringe, se convierte en el territorio ideal para encarnar universos en los que se habitan con "la felicidad de un niño que se hace preguntas" o con "la angustia de un adolescente que no sabe a qué mundo salvará el amor" (2012, p. 263). De hecho, cifran la batalla que recorre todos los textos, la que define a los otros (los partidarios de Los Soprano y Mad Men) y al nosotros (defensores de Lost y Fringe).

Cada cual sabrá qué partido toma (qué partido sigue) y por qué, pero yo quisiera que los partidarios del realismo, del aburrimiento, de la tristeza y del detalle insignificante respetaran un poco más nuestras creencias: no nos manden, amigos míos, a ver Mad Men. Nos hace odiar el mundo y nosotros somos partidarios del amor, de su multiplicación, de su reinado.

(2012, p. 263) Las clases no sólo proveen criterios para desarrollar la explicación, sino que también predisponen el gusto, algo de lo que el ensayista ya no se previene (a pesar de la disciplina esgrimida, es obvio que el yo prejuzga y que eso no queda necesariamente del lado del disvalor). Sin duda, el género solo no es suficiente: Héroes, como dijimos, se vuelve soporífera, The Walking Dead presenta "aburridos episodios de una hora". Para que una serie esté en lo más alto del ranking debe cumplir, en función de la lógica del éxito, dos requerimientos: "el éxito o el fracaso de una producción audiovisual (...) depende de dos únicas variables, guión y casting" (2012, p. 245). Esos criterios específicos, que se condensan en este imperativo, son lo que reaparecen: pueden no cumplirse en las matrices con potencialidades, como vimos a propósito de Torchwook, pero, casi arbitrariamente, no se cumplen jamás en las que carecen de ellas. Mad Men da náuseas: tiene personajes "desagradables hasta el vómito" y los diálogos son sólo "medianamente creíbles" (2012, p. 262); Los Kennedy, un melodrama que se deja ver con simpatía, es correcto: "El casting está muy bien y las actuaciones son todo lo correcto que podría esperarse. Los diálogos son creíbles y los personajes cumplen su destino" (2012, p. 264).

Ahora bien, todas estas escalas y criterios de valor, explicables, desarrollables, están cruzados por un vocabulario amoroso, que atraviesa todos los aspectos: temas, casting, locaciones.

Vocabulario que en última instancia, se cierra sobre sí mismo, sobre el gusto del espectador que escribe y que se vuelve, así, a diferencia de los otros criterios ( $\mathrm{y}$, paradójicamente, de manera similar a cómo actúan los géneros), incontestable: Doctor Who es calificada como una "encantadora remake" (también es "encantadora" la adaptación de Lost in Austen), tiene "guiones preciosos", "exquisitos" y presenta con "delicadeza" las diferentes formas de vida; Fringe se define como una "delicadísima reflexión sobre el amor y los mundos posibles" (2012, p. 261); Olivia es un personaje que se ama (Olivia "a quien amamos por su entereza a toda prueba") y que lleva incluso a la exclamación: “iOlivia, pecado mío, alma mía!” (2012, p. 265); Londres como la locación ideal, brillante: "creo que es hoy una de las ciudades más lindas de Europa (...) Tan así que no cesa de brillar en las series que seguimos" (2012, p. 260).

Televisión y literatura: Lost

En este contexto, Lost adquiere un lugar particular: explicita e intensifica generando un salto cualitativo en el abordaje. De hecho, en Textos de ocasión los ensayos que se ocupan de esta serie aparecen en otro apartado titulado "Fuera de serie: Lost", como si la clasificación a la que se quiere escapar supusiera en este caso, ya 
desde el comienzo, no un encierro en la clase sino la posibilidad de dejar entrever una cualidad diferencial. La razón de la singularización pone en el centro, sino la homogeneización, sí el cruce entre los criterios de abordaje para los diferentes objetos, y se condensa en las primeras líneas del apartado: Lost es una de las grandes experiencias estéticas y culturales de nuestro tiempo. Desde el comienzo, Lost estuvo concebida como una "experiencia" que se hacía en el interior mismo de la televisión (cuyos protocolos venía a desmontar prolijamente) como en Internet (...) La pregunta que seduce a los cientos de millones de fieles de Lost es algo que tiene que ver con el registro de lo decible después de un siglo que comprobó que la experiencia se nos ha vuelto imposible, desde el lugar mismo de esa imposibilidad histórica: la televisión. (2012, p. 267) Intensificación: la aproximación a Lost pone en primer plano, en el íncipit del apartado, el interés del ensayista por aquellos objetos que condensan "una tensión incómoda entre arte y cultura industrial"; en este sentido, parece exigir la reformulación del punto de vista móvil propuesto en el origen mediante la apelación y complejización del concepto de experiencia y la puesta en juego de la "imposibilidad", que conlleva la reaparición de las tensiones que marcan la escritura ensayística de Link en torno a la afirmación radical de un final, el reconocimiento de la existencia de finales previos y la crítica a los modos en que estos se reformulan en la actualidad.

Salto: si en "Absurdo" la axiología era un riesgo que debía tomarse para evitar los milenarismos que los mismos productos de la industria cultural vehiculizaban, Lost obligará explícitamente, a medida que se vayan desarrollando las hipótesis, a reformular el sistema de valores a partir de los finales, como si la prevención ante los mismos en tanto productos culturales se hubiera caído. Lost es postcinematográfica, existe después de "la desaparición del cine como arte"; y no puede ser leída simplemente como obra de arte, no solo porque es interior y a la vez exterior a los universales artísticos, sino porque tampoco se sabe si hoy dichos universales pueden sostenerse. El ensayista, ante este objeto que se encuentra afuera de las dos grandes clasificaciones artísticas de los siglos pasados, se entrega a los imaginarios sobre el final, pero sin el resguardo de la simulación que desarrollaba en "Pop".

Entrega que lleva, incluso, a formular una necesidad que, como vimos, no es valorable en función de los imperativos de su sistema conceptual, pero que, sin embargo, se ha ido reformulando en las búsquedas de los ensayos: Lost "propone un universo que nos pone a imaginar un orden posible, cualquier orden, para no volvernos locos" (2012, p. 268).

Es cierto, el sistema Link lo previene casi todo: Lost es un umbral -categoría que se desarrolla explícitamente en Fantasmas y que se caracteriza por articular una fuerza de desintegración que se opone al límite y que permanece como resto de la clase-. Pero tal vez, entonces, un umbral que no sólo dice la incomodidad que debería suponer sino que también la pone en juego. Es que los conceptos para abordar el objeto se acumulan. Y lo hacen, podríamos arriesgar, como nunca antes a propósito de este tipo de producto: la radicalidad esgrimida como valor convoca y se asocia a resistencia, sugestión, seducción, intensidad, densidad; a proliferación, fragmentarismo, profundidad, suspensión de todas las barreras, prolijidad; a saber como falta, moral de las formas, clasicismo, a lo "novelesco sin la novela". Y en esta acumulación necesaria y fanática son a la vez clasificaciones y cualificaciones, prevenciones y modos de abrir el contacto, en la ansiedad del ensayista por poder desvelarnos la "regla de oro" de Lost, para que dejemos de ser, en una jerarquía ya exasperada, casi al borde de lo moral, el "televidente promedio".

Y si uno de los temas que interesaba a Link en "Diario de un televidente" se cifraba en la pregunta por cómo vivir juntos, ésta vuelve a propósito de Lost, pero, en el movimiento ensayístico, el subrayado de este interrogante, no 
desemboca en la puesta en el centro del carácter emblemático ni vuelve necesario el contacto con el arte, sino que saca verdaderamente "de serie”: “¿Cómo vivir juntos?” la pregunta que resuena en los capítulos de Lost (...) es correlativa a otra, “¿cómo y para qué reproducirse?”, que son las preguntas de nuestra época. No es que Lost pretenda dignidad filosófica alguna (...) Todo lo que puede leerse en Lost (...) nos viene dado como por añadidura, sin el impulso balzaciano o wagneriano hacia la totalización tan propios del s. XIX y sin la vocación destructiva de la totalidad (paródica) tan característica del siglo XX.

(2012, p. 268) La pregunta conecta, a su vez, con un tópico que, a propósito de The Walking Dead, había sido desdeñado: la supervivencia. Pero no sólo porque la caída del vuelo 815 ha dejado sobrevivientes que al mismo tiempo, en las últimas temporadas, deberán salvarnos de la "destrucción del mundo". Tampoco porque la narración, en la sexta temporada, se está sobreviviendo a sí misma y plantea una doble temporalidad en la que supervivencia no equivale a simulacro sino que se tensiona con una verdadera "aceptación de la muerte".

La formulación del problema, y el cruce de la forma de interrogación de los dominios, va incluso más allá: Lost se postula como la narración del final de los tiempos y del más allá de la Historia, y se interroga cómo y por qué, habiendo ya perdido la humanidad sus rasgos y sus propiedades (habiendo desaparecido el "ser humano" como tal), la guerra, la violencia y la destrucción siguen existiendo. ¿En qué se funda esa supervivencia que ha perdido toda posibilidad de funcionar en relación con un "progreso" que, a todas luces, para los guionistas de la serie, ya ha cesado? (2012, p. 277) Georges Didi-Huberman al desarrollar, a partir de la escritura de Pasolini, el concepto de supervivencia (de las luciérnagas) sostiene lo siguiente: En 1975, a punto de escribir su texto sobre la desaparición de las luciérnagas, el cineasta se introducirá en el motivo -trágico y apocalíptico- de la desaparición de lo humano en el corazón de la sociedad presente "Quiero simplemente que mires a tu alrededor y tomes conciencia de la tragedia. ¿Y cuál es la tragedia? La tragedia es que no existen ya seres humanos; no se ven más que artefactos singulares que se lanzan unos contra otros".

(2012, p. 21-22) Esta tragedia se enlaza con la protesta feroz de Pasolini contra los cuerpos sobreexpuestos "a la plena luz de las sitcoms" (2012, p. 22) Resuena, entonces, en ese "desaparecido el 'ser humano' como tal”, la voz de ese autor al que Link vuelve constantemente y que en "Absurdo" era presentado como aquel que "desdeña en bloque el sistema de clasificación".

Resuena más aún si pensamos la forma en que Lost ha manejado la luz que deslumbra y enceguece y los ojos que se abren. Pero es una resonancia casi obscena (en el sentido que Hal Foster [2001] le otorga al término) porque supondría paradójicamente la plena luz como posibilidad, en una apropiación sin distancia por parte del ensayista, para llevar adelante la interrogación que mueve su escritura, de los "agenciamientos un poco demenciales" que caracterizan su objeto: una serie de televisión.

Notas

1. En la compilación del "Método" que Link realiza en Textos cautivos se elige incluir una sola entrevista, en la que se lee lo siguiente (en total coherencia con la cita de Hugo von Hofmannsthal que se transcribe en el comienzo del apartado): “¿Se reconoce más como crítico o como escritor? No hay diferencia entre una cosa o la otra. Escribo (argumentaciones, metáforas, relatos, diálogos). Después se ve qué se puede armar con todo eso (libros de ensayo, de poemas, novelas u obras de teatro)" (2012, p. 10). 
En "Arquitectura", un texto que no se compila en el libro, tal vez por su naturaleza circunstancial, puede observarse cómo el blog se caracteriza por la reunión anárquica de materiales muy diversos pero cómo, al mismo tiempo, ese material exige criterios de clasificación.

2. Se vuelve interesante, en este sentido, el lugar también paradójico que ocupa en la teoría: si Guy Debord (2008) coloca lo televisivo en los años 1970 en el centro de una sociedad del espectáculo que sigue planteando en términos de alienación, Jean Baudrillard $(1978,1997)$ lo situará en el centro de la sociedad simulacral, sociedad que ya no puede pensarse según las categorías de realidad y de representación que han regido el siglo XX y que marcaban el análisis de Debord. He trabajado más extensamente esta temporalidad singular en Con los ojos bien abiertos. Bizzio, Chejfec, Babel. Para el análisis concreto del contexto argentino con respecto al lugar de la televisión en la definición de lo actual cf. Carricarburo (2008) y Kohan (2001).

3. En "Políticas de género", Link -en función de criticar la relación de Tomás Eloy Martínez con el mercado y proponer su propia genealogía constituida por aquellos escritores en que esa relación "se vuelve realmente interesante"- sostiene lo siguiente: "En la argentina que avanza hacia el segundo centenario (...) toda relación con la cultura industrial se ha vuelto mucho más dramática y convoca, en efecto, una seriedad trágica que aparentemente todavía no estamos dispuestos a asumir. De Rayuela a Vivir afuera, Cumpleaños o Plata quemada (que marcó un límite), hay una tensión incómoda entre arte y cultura industrial.

Podría pensarse que, en el contexto del realismo, esa tensión se resuelve fatalmente en cosificación de la literatura (...) o que hay estrategias para sostener esa tensión y volverla productiva. Libros como Tres deseos de Claudio Zeiger o Costumbres de la carne de Alejandro Caravario abonarían esa hipótesis optimista"(2006, p. 152). Específicamente sobre la manera en que Link define el arte en oposición a la cultura cf. Gasparri (2013). Sobre la diferencia entre actual y contemporáneo (que la ensayística de Link parece pervertir) Cf. Agamben (2010).

4. En el único caso en que la apelación a las tecnologías y los medios masivos no desencadena un armado de redes de conexiones es cuando se aborda la relación de Puig con el cine, con el mercado y con Hollywood. Esto podría ser índice de un punto de partida: es la necesidad de apropiarse de Puig a través de la relación con las tecnologías que se piensan como masivas, lo que pone en funcionamiento el movimiento y hace que esa relación se extienda al resto del corpus.

5. Formulo los polos siguiendo las reflexiones sobre las relaciones entre cultura y literatura que, a partir de Roland Barthes y Gilles Deleuze, realiza Alberto Giordano en Roland Barthes. Literatura y poder.

6. En función de leer las tensiones y la multiplicación de las autofiguraciones es interesante destacar que, a pesar de que sus ejemplos han sido hasta aquí todos "no literarios", el ensayista se presenta exclusivamente como aquel que "le gusta pensar" el "arte experimental": "Son voces que nos interpelan, todavía, porque sostienen nuestros mismos sueños: sueñan el cielo, miran el cielo, hacen el cielo" (2005, p. 19).

7. La primera entrada que se conserva en el blog de la etiqueta "Diario de un televidente" es de enero de 2007. Sin embargo, la denominación de la etiqueta aparece ya en "Arquitectura" en marzo de 2005 y es utilizada como título de una entrada en diciembre de 2004. 
Los órdenes se superponen: la columna lateral del blog que tiene "Diario de un televidente" como título reúne algunas de las entradas anteriores a la etiqueta, pero también deja de lado otras que aparecen si se ingresa directamente a través de la misma. En esta ocasión, trabajo con las entradas reunidas en el libro bajo el mismo título (el tercer orden) en función de las tensiones que permite observar la compilación como género en la poética de Link y porque la selección no invalida la posibilidad de extender las hipótesis. Sin embargo, conviene aclarar que la selección no sólo reúne, como ocurre fundamentalmente cuando se aborda Lost, textos que en su momento aparecieron por separado, sino que también tiende a dejar en segundo plano (aunque no a borrar) la cotidianidad del espectador: la expectativa entre temporada y temporada, la inclusión de adelantos y tráileres, etcétera.

8. No parece casual la elección de este término en función de la atenta lectura que Link ha llevado a cabo de Roland Barthes y resulta interesante que, cuando se aúna, se prefiera, para dar cuenta de la relación, el placer antes que el goce (Cf. Barthes, 1998).

9. A propósito de su experiencia con Torchwook el ensayista abre un paréntesis: "cuando no me duermo yo en la mitad de un capítulo se duerme S., agobiado por sus responsabilidades de artista del momento, y al día siguiente, prácticamente nada interesantes es lo que uno tiene para contarle al otro" (2012, p. 239). La batalla en torno a los bandos que se generan a partir de las preferencias por las series se condensa en "La guerra de los Danieles".

Bibliografía

Agamben, G. (2010). “¿Qué es lo contemporáneo?”. Otra parte, 20, pp. 77-80.

Baudrillard, J. (1978). Cultura y simulacro. Barcelona: Editorial Kairos. . (1997). El otro por sí mismo. Barcelona: Anagrama.

Barthes, R. (1998). El placer del texto y Lección inaugural. México D.F.: Siglo XXI.

Carricarburo, N. (2008). Del fonógrafo a la red. Literatura y tecnología en la Argentina. Buenos Aires: Ediciones Circeto.

Catalin, M. (2014). Con los ojos bien abiertos. Bizzio, Chejfec, Babel. Rosario: Fiesta Ediciones/ CELA.

Debord, G. (2008). A sociedade do espetáculo. Comentários sobre a sociedade do espetáculo. Río de Janeiro: Contraponto.

Deleuze, G. (2002). Francis Bacon. Lógica de la sensación. Madrid: Arena Libros. Didi-Huberman, G. (2012). La supervivencia de las luciérnagas. Madrid: Abada.

Foster, H. (2001). El retorno de lo real. La vanguardia a finales de siglo. Madrid: Akal.

Gasparri, J. (2013). "Las aventuras (in)formales de Linkillo La realidad como invención”. En Contreras, S. (Ed.), Realismos, cuestiones críticas. Cuadernos de seminario 2 (179-208). Rosario: CELA/Humanidades y Artes 


\section{Ediciones.}

Giordano, A. (1995). Roland Barthes. Literatura y poder. Rosario: Beatriz Viterbo.

Kohan, M. (2001). "La realidad en directo”. Milpalabras, 2, pp. 52-56.

Link, D. (1994). La chancha con cadenas. Doce ensayos de literatura argentina. Buenos Aires: Del Eclipse. (2005). Clases. Literatura y disidencia. Buenos Aires: Norma. (2005, 1 de marzo). "Arquitectura". Recuperado de http://linkillo.blogspot.com.ar/2005/03/arquitectura.html (2006). Leyenda. Literatura argentina: cuatro cortes. Buenos Aires: Entropía.

. (2009). Fantasmas. Imaginación y sociedad. Buenos Aires: Eterna Cadencia.

(2012). Textos de ocasión. Buenos Aires: El cuenco de plata.

Manovich, L. (2006). El lenguaje de los nuevos medios de comunicación. La imagen en la era digital. Buenos Aires: Paidós.

Nancy, J. L. (1993). The birth to presence. Standford: Standfor University Press. . (2003). Corpus. Buenos Aires: Arena Libros. . (2007). 58 indicios sobre el cuerpo. Extensión del alma. Buenos Aires: Ediciones La Cebra.

Rancière, J. (2010). El espectador emancipado. Buenos Aires: Manantial.

Abstract:

This paper analyzes the relationship between television, art and literature in some essays written by Daniel Link. In the first place, I propose an overview from the postulate, in relation to television, of the need to create a "mobile point of view" held in La chancha con cadenas to its accomplishment in Clases. This overview emphasizes the ways in which the essayist defines gender and class. Later, I analyze texts that consider television series as an object. Finally, I examine the Link's need of creating scales of value, how they are constituted and the uniqueness that Lost acquires in this context.

Key words:

television - art - culture - artistic value - essay - Daniel Link.

Resumo:

Este artigo busca analisar o lugar que ocupa a televisão na relação entre a arte e a literatura na produção ensaística de Daniel Link. Para isso, em primeiro lugar, será realizado uma retomada a partir da aplicação, em 
relação com a televisão, da necessidade de um "ponto de vista móvel", que ocorre nos ensaios La chancha con cadenas, até a forma que este mesmo ponto se realiza em Clases. Este caminho tem como ponto central os modos de relacionamento do ensaísta com o que ele acaba por definir como gêneros e classes.

Numa segunda parte, serão abordados os textos que têm especificamente a série televisiva como objeto. São analisadas, aqui, a necessidade do ensaísta de estabelecer escalas de valor, os modos nos quais essas se constituem e a singularidade que, neste contexto, apresenta o tratamento de Lost.

Palavras chave: televisão - arte - cultura - valor artístico - ensaio - Daniel Link.

Daniel Link y la televisión:ensayos entre la clase y la cualificación fue publicado de la página 35 a página49 en Cuadernos del Centro de Estudios de Diseño y Comunicación № 61 